\title{
Study on Long-term Mechanism for Voluntary Service of College Students in Children's Welfare Work
}

\author{
Haizhou Bao \\ Qianjiang College, Hangzhou Normal University, Hangzhou, 310036, China \\ hunter2011@foxmail.com
}

Keywords: College students, Voluntary service, Children's welfare work, Long-term mechanism

\begin{abstract}
Voluntary service of college students in children's welfare work is a manifestation of colleges and universities serving the society, which can not only train personal quality of college students, but also produce important influence on the construction of socialist spiritual civilization in China. However, the current voluntary service of college students in children's welfare work lacks a supporting mechanism. Therefore, voluntary activities seem too random. This paper mainly conducts brief analysis on the significance and existing problems of voluntary service of college students in children's welfare work and measures to be taken for the establishment of long-term mechanism.
\end{abstract}

\section{Introduction}

As an important constituent part of volunteer group, college student volunteers have important influence on the quality and level of volunteer service. Moreover, the construction of Chinese society with spiritual civilization requires college students' positive participation in volunteer service and contribution to national development. With economic development of China and the improvement of ideological and cognitive level of people, Chinese voluntary service industry has developed rapidly. However, as Chinese voluntary service is still in the development stage, there are many problems. Therefore, it is very necessary to establish a perfect long-term mechanism for voluntary service of college students in children's welfare work.

\section{Significance of participation of college students in voluntary activities of children's welfare work}

Good for improving personal quality. Voluntary service of college students in children's welfare work can help college students to have profound reaction and understanding of their own development defects in practical activities so as to constantly overcome their shortcomings and gradually improve their quality ${ }^{[1]}$.Moreover, college student volunteers can also learn fine quality of other volunteers in the process of participating in children's welfare work. This has important influence on the improvement of quality of college students. In addition, they can also connect the knowledge learnt and practical activities in the process of attending voluntary activities. This has important significance for the improvement of their abilities.

Good for establishing harmonious society. Currently, China is building harmonious socialist society. The establishment of long-term mechanism for voluntary service of college students in children's welfare work can effectively attract college students to participate in welfare work. This can not only produce important influence on individual development of college students, but also greatly promote the construction of Chinese socialist spiritual civilization and the formation of good atmosphere in the society and have realistic significance for the construction of harmonious socialist society in China.

Existing problems of participation of college student volunteers in activities of children's welfare work

Lack understandings of voluntary culture. With the improvement of new media technology and ideological and cognitive level in recent years, Chinese volunteer activities have developed rapidly. 
However, due to the late start of Chinese volunteer service activities, there are many deficiencies. In terms of the current status, many college students in China lack profound understandings of voluntary culture and are unaware of the importance of volunteer activities, which influence their initiative in volunteer activities.

Lack a perfect management system. Management system is an important basis for the engagement of people in work. Though volunteers in some regions have great initiative and work carefully and responsibly when participating in volunteer activities, the lack of a perfect management system causes disorder and low efficiency during their participation in voluntary activities. In addition, due to the incompleteness of management system, some volunteers cannot receive training in time. This has important influence on the quality and efficiency of voluntary service work.

Lack a sound incentive mechanism. The main function of incentive mechanism is to encourage college students to participate in children's welfare work. However, due to the incompleteness of the current incentive mechanism, the initiative of college student volunteers is not mobilized well. Moreover, many college students expect to gain other's recognition when participating in voluntary activities. However, the incompleteness of system causes the failure to meet their demands and dampens their enthusiasm about attending voluntary activities ${ }^{[2]}$.

\section{Measures for establishing long-term mechanism for voluntary service of college students in children's welfare work}

Establish complete publicity mechanism. People's understandings of volunteer service industry can directly influence the service level of volunteer industry and have important influence on healthy and long-term development of the industry. Therefore, it is very necessary to strengthen the publicity for college students and establish a complete publicity mechanism. Relevant department can improve the publicity mechanism in the following aspects:

First, exert the guiding function of government. The government can expand publicity approaches of voluntary service with resources such as new media to allow more college students to know the significance of voluntary activities and methods for participating in voluntary service industry. This can encourage college students to participate in voluntary service activities. In addition, the government can also strengthen the guidance over social work positively, create a good social environment for college students' participation in voluntary service industry and stimulate the implementation of all-round voluntary activities while encouraging them to attend voluntary activities.

Second, develop the spirit of volunteerism and exert the function of example ${ }^{[3]}$.Relevant department can set an example by encouraging and praising excellent volunteers, make college students admire such excellent volunteers and then impel them to participate in voluntary service industry positively, serve with the spirit of "devotion to others and self-improvement" and implement the spirit of volunteerism in voluntary service so as to promote the establishment of college students' voluntary service system.

Third, strengthen encouragement and support of colleges and universities. Colleges and universities can strengthen moral education for college students in teaching activities, guide them to establish a correct world view, outlook on life and value, show achievements of moral education through voluntary service and guide college students to participate in voluntary activities consciously. In addition, colleges and universities can also popularize the spirit and concept of voluntary service and publicize voluntary service culture positively among college students by issuing authoritative information to them.

Forth, innovate publicity methods. When publicizing voluntary work, the government and colleges and universities can innovate publicity forms based on the current status of social development so that college students accept contents of publicity more easily. For example, when publicizing the spirit of volunteerism, they can make a short video or animation with modern advanced network technology and reflect the spirit in real cases so as to encourage them to attend voluntary activities spontaneously. 
Establish complete management mechanism. The establishment of management system for voluntary service of college students in children's welfare work can produce important influence on orderly management and training of volunteer work and the improvement of overall ability level of volunteers. Therefore, relevant department can improve the management mechanism in the following aspects:

First, establish network service platform. Relevant department can establish children's welfare work website with current advanced network technology, disclose the information of children needing help on the website publicly and show achievements of volunteer service so as to allow college students to see their own work achievements and encourage their work. For example, we have established WeChat public platform for better publicity, on which the information of children especially needing attention is released so that volunteers can pay attention in time, communicate with and support those objects of help and improve the timeliness of voluntary service. In addition, volunteer service platform can also allow more college students to have a clear understanding of volunteer work and positively promote the recruitment and use of volunteers.

Second, establish scientific registration system. Volunteer registration system is a method widely used in the world, which has a good effect. The establishment of volunteer registration system has important influence on the organization and management of volunteer work and can positively promote orderly implementation of volunteer activities and improve the quality and level of volunteer service.

Third, establish strict training system ${ }^{[4]}$.The government, social organizations and colleges and universities can provide positive training for interested volunteers and make them realize the significance and contents of volunteer work and basic quality to be possessed by volunteers in the training process. We will provide volunteers with professional trainings such as service salon, quality development and seminar periodically so as to make college students realize self-sublimation in the training process, arouse their interest and help them master basic requirements for the participation in voluntary activities and lay a solid foundation for their high-efficiency work implementation in the future.

Forth, establish effective evaluation system. The establishment of evaluation mechanism can allow relevant department to master the service status of volunteers in time and then help college students to grasp the blind zone of service and produce important influence on the establishment of effective service mechanism. We have designed a comprehensive service quality evaluation sheet in the process of volunteer activities. Voluntary service is comprehensively evaluated according to service receiver, welfare house, school and volunteer. The evaluation result is used as basis for annual assessment. Moreover, relevant department can arrange work for college students according to their evaluation status and strong points so as to realize rational resource allocation.

Establish complete incentive mechanism. Many college students expect to gain the recognition and respect of the society and surrounding people by attending volunteer activities. Colleges and universities can establish a mechanism according to such psychological characteristics of college students and encourage them to attend volunteer activities positively. Relevant department can improve the incentive mechanism in the following aspects:

First, establish appraisal system. Relevant department can evaluate behaviors of college students according to their daily performance and service status, then give appropriate spiritual and material reward to college students with excellent performance according to the whole situation of evaluation and recognize behaviors of college students through reward so as to encourage other college students, impel them to treat work seriously in voluntary service and improve the service level of college students. For example, the Department of School Work gives a reward in our volunteer activities according to specific performance of volunteers, e.g. rewards those with excellent performance in annual award ceremony, issues certificate of honor and takes rewarding and subsidy measures such as travel allowance for volunteers, so as to encourage and support volunteer activities and make it implemented effectively in the long term.

Second, establish accreditation system. Relevant department is required to improve file management of college students and add voluntary service status of college students to their files, 
which is used as an indicator for measuring their comprehensive quality and can add luster to their participation in work in the future. In addition, relevant department can issue a corresponding service certificate to college students with qualified performance, praise excellent college students through media, further affirm the value of college student volunteers and give affirmation to behaviors of college students. In addition, we can include volunteer service in the credit of the second classroom with the common accreditation of the Department of School Work and Teaching Department if volunteers have carried out a certain amount of social services. The establishment of accreditation system such as file and credit can make the value of students serving the society be affirmed by the school to a certain extent and stimulate the enthusiasm of students about voluntary service greatly.

Third, establish service feedback system. Relevant department can establish an effective feedback mechanism to reflect college students' voluntary behaviors, evaluate the service status of college students appropriately according to their performance, point out deficiencies so that they can be corrected and praise college students for their excellent performance. In addition, relevant department can make proper adjustments for deficiencies of voluntary activities according to information fed back by college students so as to provide more help for children needing help.

Forth, establish effective communication system. The establishment of communication system requires not only internal communication among volunteers, but also communication with children. Most children needing help have some psychological problems. Communication can reduce inner confusion of children effectively and help them walk out of the shadow. College student volunteers can learn from others' strong points to offset their weakness through internal communication, promote the improvement of personal level and make more contributions to voluntary service work. For example, drawing is the instinct of children. Our volunteers have made a lot of drawings on the wall of children welfare association to describe the wonderful life and future. We allow children to see the wonderful future and sow a seed of happiness in the heart through drawing. Such communication way cannot be realized by textbook and language communication. Therefore, it has a unique effect.

Establish complete guarantee system. Many college students still require family support in terms of material guarantee. Therefore, to arouse the enthusiasm of college students about participating in voluntary service activities, it is essential to establish a complete guarantee system. Therefore, relevant department is required to improve the system of voluntary service of college students in children's welfare work in the following aspects:

First, guarantee in legislation. This requires the state to attach more importance to volunteer service work and establish matching law based on the practical situation of Chinese volunteer service work so as to provide guarantee for volunteer work legally, make laws available to follow in volunteer service work and effectively standardize the work.

Second, guarantee in policy. This requires the local government to include volunteer service work in daily work, give encouragement to volunteer service work in policy and support local volunteer service work by providing it with fund guarantee. In addition, it can effectively drive the initiative of local enterprises in public welfare establishments under the support of the government so as to guarantee the smooth implementation of public welfare work.

Third, guarantee in cost. Fund is the premise and foundation of college student volunteer work, which concerns the operation of the whole voluntary service system. Therefore, it has important influence on voluntary service work. Therefore, relevant department can establish children's welfare work funds, use all donations and assisting funds for children's welfare work, realize the use of fixed funds for a fixed purpose and provide fund guarantee for the implementation of children's welfare work. For example, we have added special service funds for volunteers to funds for student activities to guarantee basic activity conditions. In addition, we also raise funds for activities through professional charity performance. For example, “Mass Response to Welfare” artistic performance activity implemented by us for a long time is an important measure for raising funds.

Forth, guarantee in rights and interests. Relevant department should illustrate legal rights and interests of volunteers in detail in legislative provisions established and protect such rights and interests legally. In addition, local government should provide material guarantee for college student 
volunteers so as to arouse their enthusiasm about participating in volunteer activities and promote long-term development of volunteer activities.

\section{Conclusion}

In conclusion, with social development and progress, Chinese colleges and universities should not only pay attention to talent and learning of college students, but also attach importance to their moral character in the process of talent training. When serving children's welfare work voluntarily, college students can show their knowledge and meanwhile exercise their practical abilities and promote the improvement of their ideological quality. This has important influence on the stability and development of Chinese society. Relevant department is required to establish a complete development mechanism to promote college students' initiative in voluntary activities, make contributions to the society and achieve their personal value.

\section{Acknowledgments}

This topic is a planning topic of theoretical research on civil affair policies of Zhejiang named Study on Long-term Mechanism for Voluntary Service of College Students in Children's Welfare Work, No. ZMYB201520.

\section{References}

[1] T.S. Pang, H.X. Pan, Q. Xu et al. Data Analysis of College Student Voluntary Service Motivation Scale and Prospect - Take College Students in Zhejiang for Example. Knowledge Economy, 2011(21):170-171.

[2] G.W. Li. Participation of College Students in Voluntary Activities and Influencing Factors Findings of Sampling Survey of a College. Journal of Beijing Youth Politics College, 2010,19(3):11-18.

[3] C.C. Wang, Y.J. Zhang. Status of College Student Voluntary Service Work and Promoting Strategies - Take Investigation and Analysis of College Students in Jiangning College Town for Example. Economic Research Guide, 2015(4):175-176.

[4] S.R. Zhang. Investigation and Research on College Student Voluntary Service - Take Nanjing University of Information Engineering for Example. Edge, 2012(16):16-18.

[5] H. Peng. Brief Analysis on Role of Volunteer Activities in All-round Development of College Students. Impart Knowledge and Educate People (Higher Education Forum), 2010(10):84-86. 